\title{
Trypsin Protein Cleavage Reagent
}

National Cancer Institute

\section{Source}

National Cancer Institute. Trypsin Protein Cleavage Reagent. NCI Thesaurus. Code C161893.

A protein cleavage reagent comprised of the a form of the serine proteinase trypsin that cleaves proteins into peptides at the C-terminal side of a lysine or arginine residue unless that residue is followed by a proline. 